\title{
Unmet need for family planning and its associated factor among women of reproductive age in Debre Berhan Town, Amhara, Ethiopia
}

\author{
Solomon Adanew Worku* ${ }^{1 *}$, Sindew Mahmud Ahmed ${ }^{2}$ and Tizebt Fisseha Mulushewa ${ }^{2}$
}

\begin{abstract}
Objective: Unmet need refers to fecund women who either wish to postpone the next birth (spacers) or who wish to stop childbearing (limiters) but are not using a contraceptive method. The aim of this study was to assess the unmet needs of family planning and identify associated factors in Debre Berhan town among women in reproductive age. The community-based cross-sectional study design was used among 411 study participants (women with reproductive age) at Debre Berhan town. A systematic sampling technique was used to select the households. Bivariate and multivariable analyses were done to determine the association of each independent variable with the dependent variable.

Results: The overall unmet need for family planning among women in reproductive age groups was found to be 30.9\%. Occupational status AOR $=13.992$ (1.054-185.833), from whom the respondents got information about family planning $A O R=0.018$ (0.002-0.170), having a discussion with husband $A O R=16.692$ (2.911-95.713) and support from husband $A O R=0.005(0.001-0.025)$ was significantly associated with the outcome variable. The level of unmet need for family planning in the study area is still high compared to the target set (10\%) in the national family planning guide plan for Ethiopia.
\end{abstract}

Keywords: Family planning, Limiting, Spacing, Unmet need

\section{Introduction}

Unmet need refers to fecund women who either wish to postpone the next birth (spacers) or who wish to stop childbearing (limiters) but are not using a contraceptive method $[1,2]$. Many women who are sexually active would prefer to avoid becoming pregnant but are not using any method of contraception. These women are considered to have an unmet need for family planning [3].

Globally an estimated 80 million unintended pregnancies, both mistimed and unwanted, occur each year. Unintended pregnancy and births have grave

\footnotetext{
*Correspondence: solhabtu@gmail.com

1 Department of Midwifery, College of Health Science, Debre Berhan University, Debre Berhan, Ethiopia

Full list of author information is available at the end of the article
}

consequences to the mother and family and are global social and health burdens. It is much more likely to end in potentially unsafe abortion [4].

Sub-Saharan Africa, 25 percent of women of reproductive age who are married or in a union have an unmet need for family planning. Also, four countries in Latin America and the Caribbean, eight countries in Asia and four countries in Oceania have an unmet need for family planning above 20 percent according to the most recent data available $[5,6]$.

Report from EDHS 2016 reveals that $58 \%$ of currently married women age 15-49 have a demand for family planning. Thirty-six percent of currently married women are already using a contraceptive method either to space (22\%) or to limit births (14\%). Unmet need for currently married women age 15-49 is lowest in Addis Ababa (11\%) and highest in Oromia region (29\%) [7]. 
Unmet need has a direct impact on the total fertility rate. It is believed that if unmet need were eliminated, fertility would decline substantially. From a policy perspective, reducing unmet need for family planning is important for both achieving demographic goals and enhancing individual rights [8].

To reduce the proportion of unmet need for family planning, knowing the current level and its determinants is a prerequisite. This study was conducted to investigate the magnitude and associated factors of unmet need for FP among reproductive-age women in Debre Berhan town.

\section{Main text}

\section{Study design, study population and sampling}

The study was conducted from March to April 2018 in Debre Berhan town which is located in north shoa zone of Amhara regional state of Ethiopia. The town is located $130 \mathrm{~km}$ away from the capital city of Addis Ababa on the North East direction along the main road to Wollo and Tigray [9]. The community-based cross-sectional study design was employed. All women's age 15-49 in the selected sample Kebeles were our study population. To determine the number of women to be included in the study a single population proportion formula was used. The final sample size was 411 [2]. In this study unmet need for family planning refers to fecund women who either wish to postpone the next birth or who wish to stop child bearing but are not using a contraceptive method. A systematic sampling technique was used to select the households $(\mathrm{HH})$, and a woman in reproductive age in the selected households was interviewed.

\section{Data collection and data analysis}

Data were collected by trained data collectors. Both open and close-ended semi-structured interview administered questionnaire was utilized for data collection. The questionnaire was developed in English based on literature review [2, 10-12] and translated into Amharic, then back to English to check for consistency. Finally, the Amharic version was used for data collection.

The data was intensively cleaned up before its analysis and was entered using Epi Data 3.1 version and analysis was carried out using statistical package for social sciences (SPSS) version22. Frequency distribution tables and statistical graphs were used to describe some variables. Cross-tabulation and logistic regression were done to examine the association between dependent and independent variables and significant variables ( $\mathrm{p}$-value less than 0.2) were entered into multivariate analysis and adjusted odds ratio (AOR) was seen to check confounding factors. A 95\% confidence level and a p-value of less than 0.05 were considered to get statistically significant.

\section{Results}

\section{Socio-demographic characteristics}

A total of 411 women were enrolled in this study with a response rate of $100 \%$. Their mean age was found to be $29.4 \pm 7.65$ years. The majority of them were orthodox in religion $333(81.0 \%)$. In terms of marital status 238 (57.9\%) married and Housewives 120 (29.2\%). About 200 (48.7\%) of the respondents were complete college and above. Almost all of the respondents 395 (96.1\%) had access to mass media (Table 1).

\section{Reproductive history}

From the total of respondents, 276 (67.2\%) of the participants were experienced pregnancy in their lifetime. From those who experience pregnancy 85 (30.8\%) of them experience pregnancy one times. Majority of the respondents $245(88.8 \%)$ gave birth. About 58 (21\%) of respondents who were experienced pregnancy had a history of abortion. Twenty-seven $(6.5 \%)$ of the interviewed women were pregnant and all of the pregnancy was wanted. Majority of the respondents 398 (95.6\%) of had information about family planning. From those who had got information about family planning 155 (39.4\%) of the respondents got from health workers and had got a discussion about how to use family planning from health providers 193 (91.9\%). From those who don't use family planning the major reason raised by the respondents was fear of side effect, 56 (27.9\%) and least majority doesn't utilize family planning because they want to have more children.

\section{Unmet need for family planning}

Unmet need was calculated by summing the number of women who do not use family planning as a result fear of side effects, prohibition from husband, prohibition from religion and inaccessibility. The overall unmet need for family planning among women in reproductive age groups was found to be $30.9 \%$ (Fig. 1).

\section{Factors affecting the unmet need for family planning}

After controlling other variables among the independent variables only, occupational status, a place from where heard about family planning, had a discussion with husband and got support from your husband to use family planning maintained their association with unmet need for family planning after controlling other confounders. A respondent whose occupation is employed was found to be 13.992 times more likely to had an unmet need for family planning compared with self-employed. $\mathrm{AOR}=13.992(1.054-185.833)^{*}$.

Women who heard information about family planning from health worker $98.2 \%$ less likely to had an unmet 
Table 1 Socio demographic characteristics of the respondents in Debre Berhan town April $2018 \mathrm{~N}=411$

\begin{tabular}{|c|c|c|c|}
\hline Variable & Response & Frequency & Percent \\
\hline \multirow{4}{*}{$\begin{array}{l}\text { Age of respondents } \\
N=411 \\
\text { Mean age }=29.4 \text { years }\end{array}$} & $\leq 25$ & 147 & 35.8 \\
\hline & $26-35$ & 158 & 38.4 \\
\hline & $36-45$ & 98 & 23.8 \\
\hline & $\geq 46$ & 8 & 2 \\
\hline \multirow{5}{*}{$\begin{array}{l}\text { Religion of the respondents } \\
N=411\end{array}$} & Orthodox & 333 & 81.0 \\
\hline & Protestant & 41 & 10.0 \\
\hline & Muslim & 29 & 7.1 \\
\hline & Catholic & 5 & 1.2 \\
\hline & Other & 3 & 0.7 \\
\hline \multirow{4}{*}{$\begin{array}{l}\text { Marital status of the respondents } \\
N=411\end{array}$} & Single & 147 & 35.8 \\
\hline & Married & 238 & 57.9 \\
\hline & Separated & 9 & 2.2 \\
\hline & Widowed & 17 & 4.1 \\
\hline \multirow{5}{*}{$\begin{array}{l}\text { Educational status of the respondents } \\
N=411\end{array}$} & Can't read and write & 19 & 4.6 \\
\hline & Can read and write & 41 & 10.0 \\
\hline & Primary school & 58 & 14.1 \\
\hline & Secondary school & 93 & 22.6 \\
\hline & College and above & 200 & 48.7 \\
\hline \multirow{4}{*}{$\begin{array}{l}\text { Occupational status of respondents } \\
N=411\end{array}$} & House wife & 120 & 29.2 \\
\hline & Student & 66 & 16.1 \\
\hline & Employed & 167 & 40.6 \\
\hline & S Self-employed & 58 & 14.1 \\
\hline \multirow{5}{*}{$\begin{array}{l}\text { Husband education level } \\
N=238\end{array}$} & Can't read and write & 5 & 2.1 \\
\hline & Can read and write & 9 & 3.8 \\
\hline & Primary school & 33 & 13.8 \\
\hline & Secondary school & 53 & 22.3 \\
\hline & College and above' & 138 & 58.0 \\
\hline \multirow{2}{*}{$\begin{array}{l}\text { Access to mass media } \\
n=411\end{array}$} & Yes & 395 & 96.1 \\
\hline & No & 16 & 3.9 \\
\hline
\end{tabular}

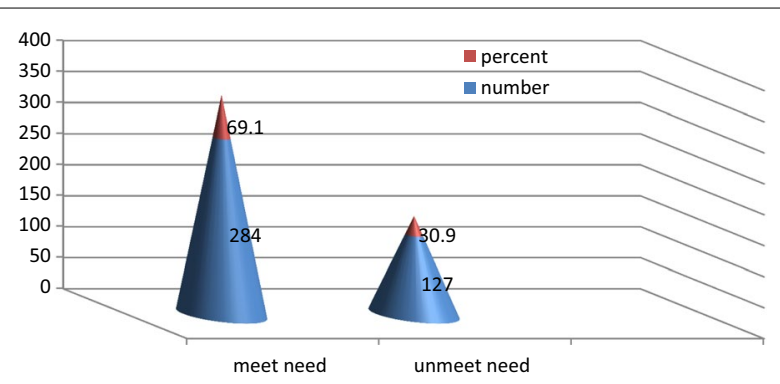

Fig. 1 Respondents over all unmet need for family planning among women in reproductive age group in Debre Berhan Town April 2018 $(n=411)$

need for family planning compared with those who got from community AOR $=0.018 \quad(0.002-0.170)^{* * * *}$. The respondent who had a discussion with their husband about family planning 16.692 times more likely to had an unmet need for family planning compare with those who had no discussion with their husbands AOR $=16.692$ $(2.911-95.713)^{* * *}$.

Respondents who got support from husband $99.5 \%$ less likely to had an unmet need for family planning compared with who had no support. AOR =0.005 (0.001$0.025)^{* *}$ (Table 2).

\section{Discussion}

The present study intended to calculate the unmet need for family planning in Debre Berhan Town. The overall unmet need was found to be $30.9 \%$ which was much higher than the national prevalence which was $22 \%$ of currently married women have an unmet need for family planning [7]. This variation is due to the EDHS includes only married women. But ours include married and unmarried women. And higher in the study conducted in Mekele which was $21.4 \%$, the study in Dangela (17.4\%) $[2,11,13]$. The variation may be due to the difference 


\begin{tabular}{|c|c|c|c|c|c|c|}
\hline \multirow[t]{2}{*}{ Variables } & \multirow[t]{2}{*}{ Alternative response } & \multicolumn{2}{|c|}{$\begin{array}{l}\text { Unmet need } \\
\text { planning }\end{array}$} & \multirow[t]{2}{*}{$\operatorname{COR}(95 \% \mathrm{Cl})$} & \multirow[t]{2}{*}{ AOR $(95 \% \mathrm{Cl})$} & \multirow[t]{2}{*}{$\mathrm{p}$-value } \\
\hline & & Yes & No & & & \\
\hline \multirow[t]{4}{*}{ Occupation } & Housewife & 36 & 84 & $2.333(1.037-5.250)$ & $6.751(.485-93.938)$ & 0.155 \\
\hline & Student & 33 & 33 & $5.444(2.306-12.854)$ & 68.108 (0.478-9697.946) & 0.095 \\
\hline & Employed & 49 & 118 & $2.261(1.031-4.957)$ & $13.992(1.054-185.833)^{*}$ & 0.046 \\
\hline & Self-employed & 9 & 49 & 1.00 & 1.00 & \\
\hline \multirow[t]{6}{*}{ From where do you hear } & From mass media & 48 & 97 & $0.2830(0.111-0.720)$ & $0.185(0.030-1.142)$ & 0.069 \\
\hline & From health worker & 22 & 133 & $0.095(0.036-0.252)$ & $0.018(0.002-0.170)^{* * *}$ & $\leq 0.001$ \\
\hline & From school & 21 & 26 & $0.462(0.163-1.308)$ & $0.044(0.001-1.141)$ & 0.115 \\
\hline & From friends & 8 & 15 & $0.305(0.090-1.033$ & $0.267(0.028-2.516)$ & 0.249 \\
\hline & From husband & 1 & 0 & $923,128,494.031$ & $7,447,944,062.228$ & 1 \\
\hline & From community & 14 & 8 & 1.00 & 1.00 & \\
\hline \multirow{2}{*}{$\begin{array}{l}\text { Have you discussed fam- } \\
\text { ily planning with your } \\
\text { husband }\end{array}$} & Yes & 38 & 170 & $0.540(0.253-1.254)$ & $16.692(2.911-95.713)^{* *}$ & 0.02 \\
\hline & No & 12 & 29 & 1.00 & 1.00 & \\
\hline \multirow{2}{*}{$\begin{array}{l}\text { Have you got support from } \\
\text { your husband to use family } \\
\text { planning }\end{array}$} & Yes & 7 & 162 & $0.032(0.013-0.079)^{*}$ & $0.005(0.001-0.025)^{* *}$ & $\leq 0.001$ \\
\hline & No & 40 & 30 & 1.00 & 1.00 & \\
\hline
\end{tabular}

* Significant variables

in study subjects in which those studies include only married reproductive age groups but, our include all reproductive age groups. It is also higher the study in Kishanganj district, Bihar, India which was $23.9 \%$ [14]. This variation is may be due to the difference in Socio-demographic characteristic of the study subjects.

The finding of the study was low compared with the study conducted in Sudan Using West off model the total unmet need was estimated at 44.8\%, in Arba Minch $(41.5 \%)[2,10]$. The variation may be due to the difference in sample size as well as socioeconomic characteristics of the study participants.

Our study reveals that a respondent whose occupation is employed was found to be 13.992 times more likely to had an unmet need for family planning compared with self-employed. This finding is higher than the study done in Dangla that reveals occupationally women who are none employed found to be 6.81 times more likely to had unmet need compared with respondents who was employed [11]. The result of our study is different from the study in Dangla due to the difference in sample size and Socio-demographic characteristics of respondents or this are due to employed women may have no time and busy by work.

The present study reveals that respondents who got support from husband $99.5 \%$ less likely to had an unmet need for family planning compared with who had no support. This is supported by the study conducted in Pakistan and Areba Minch [2, 15]. This study revealed that women whose partner had a non-supportive attitude about contraceptives use were more likely to have an unmet need for family planning compared to women whose partners had a supportive attitude.

The present study reveals that respondent who had a discussion with their husband about family planning 16.692 times less likely to have an unmet need for family planning compare with those who had no discussion with their husbands. This is inlined with the study conducted in Nigeria [16]. This implies that decisions around family size and fertility will enhance family planning utilization. The present study also reveals that there is a significant relationship between unmet need for family planning and from whom respondents heard information for family planning. It indicates that Women who heard information about family planning from health worker $98.2 \%$ less likely to had an unmet need of family planning compared with those who got from community This was not discussed with other studies. And it reflects that discussion with health provider will enhance family planning utilization and decrease unmet need.

Our study reveals that there was no significant association between unmet need for family planning and the number of lived children. But studies in Kenya, Areba Minch, Sudan \& Uganda reveals that the likelihood of having unmet need seemed to increase with the number of living children. Couples who have more living children are more likely to have an unmet need than the ones who have fewer children or none at all. Couples with more 
children have a greater desire to stop childbearing, which may not be translated into actual practice, because of other factors affecting the decision to use family planning, or those that affect the supply and accessibility of family planning $[2,10,17,18]$. In our case, it may be due to an inadequate sample size that only a small portion of the respondents had living children.

In this study even if they are not significant Husband's disapproval, prohibition from religion and fear of side effects were found to be the common reasons behind the unmet need for family planning among the respondents of the present study. This is supported by the studies in Pakistan, Sudan, Uganda and Bangladesh [4, 10, 15, 17]. The study in Saudi Arabia reveals that major reason why women do not go in for use of a contraceptive despite their desire to do so revealed lack of knowledge and lack of access to family planning methods, fear of side effect of contraceptives, religious prohibition, and husband's disapproval as commonly stated reasons [18].

\section{Conclusions}

The study reveals that there was a high prevalence of unmet need in the study area $30.9 \%$ and family planning utilization rate was found to be $51.1 \%$. Family planning among reproductive-age women was not met. Variables like occupation, support from the husband, from who heard about family planning and had a discussion with husband about family planning have a significant association with unmet need.

\section{Recommendation}

It is important to strengthen counseling and partner involvement in Debre Berhan Town to reduce unmet need for family.

\section{Limitations}

The men were not included as participants to understand their perception towards the total unmet need for family planning. The study did not asses separately unmet need for spacing or limiting because the tool doesn't have a parameter to assess these variables.

\section{Abbreviations}

AOR: Adjusted Odds Ratio; EDHS: Ethiopia Demographic and Health Survey; $\mathrm{HH}$ : households; SPSS: statistical package for social science.

\section{Authors' contributions}

SA, SM and TF conceived and designed the study, identify the study, extract the data, analyzed the data and wrote the manuscript. All authors of this original manuscript authorized the final version of the manuscript. All authors read and approved the final manuscript.

\section{Author details}

${ }^{1}$ Department of Midwifery, College of Health Science, Debre Berhan University, Debre Berhan, Ethiopia. ${ }^{2}$ Departments of Nursing, College of Health Science, Debre Berhan University, Debre Berhan, Ethiopia.

\section{Acknowledgements}

We would like to thank Debre Berhan University Institute of medicine and health sciences. Then our hot and warm gratitude goes to the college of health sciences and department of Midwifery for favoring all conditions to conduct this research. Our special appreciation extends to extend to all organizations and individuals who helped us from the beginning to the end of this work. Last but not least our deep thanks reaches to the respondents who provide a genuine response without hesitation.

\section{Competing interests}

The authors declare that they have no competing interests.

\section{Availability of data and materials}

The datasets used and/or analyzed during the current study are available from the corresponding author on reasonable request.

\section{Consent for publication}

Not applicable.

\section{Ethics approval and consent to participate}

Ethical clearance and approval were obtained from the Ethical committee of Debre Berhan University. After explaining about the purpose, the possible benefit of the study and confidentiality, written informed consent was obtained from study participants prior to an interview; for minor's participants, the consent was obtained from parent/guardian on behalf of participants. All the information obtained from each study participant was kept confidential throughout the process of study, and to assure confidentiality the name of the participant was replaced by code.

\section{Funding and sponsorship}

There was no funding or sponsoring organization in this paper.

\section{Publisher's Note}

Springer Nature remains neutral with regard to jurisdictional claims in published maps and institutional affiliations.

Received: 5 January 2019 Accepted: 11 March 2019

Published online: 15 March 2019

References

1. Lata K, Barman SK, Ram R, Mukherjee S, Ram AK. Prevalence and determinants of unmet need for family planning in Kishanganj district, Bihar, India. Glob J Med. 2012;1:29-33.

2. Shifa GT. High unmet need for family planning and factors. Glob J Med Sci. 2014;14(4):13.

3. Bhattacharya SK, Ram R, Goswami DN, Gupta UD, Bhattacharyya K, Ray S, et al. Study of unmet need for family planning among women of reproductive age group attending immunization clinic in a medical college of Kolkata. Indian J Commun Med. 2006;31(2):31-3.

4. Mahmoud H, Elweshahi T, Ismail G, Saad S, Sadek E, El-sharkawy OG. Unmet need for postpartum family planning in Alexandria, Egypt. Alexandria J Med 2017;0-4. http://dx.doi.org/10.1016/j.ajme.2017.03.003 Accessed 15 Jan 2018.

5. Tiwari S. Factors influencing the unmet need for family planning. 2012; (Hel 3950).

6. United Nations, Department of Economic and Social Affairs, Population Division. Meeting Demand for Family Planning. 2013 No 2013/6.

7. Central Statistics Agency. Report of 2016 Ethiopian Demographic and Health Survey (EDHS) July 2017.

8. Uddin MS, Ahmed T, Kibria MG. Factors associated with the unmet need for family planning and its impact on population growth in Bangladesh. Bangladesh J Sci Res. 2011;24(1):75-86.

9. CSA. Amahara-Ethiopia demography and health. 2007. http://www. ethiodemographyandhealth.org/Amhara.html. Accessed 8 Jan 2014.

10. Ali AAA, Okuda A. Factors affecting the unmet need for family planning in Eastern Sudan. BMC Public Health. 2013;13:102.

11. Genet E, Abeje G, Ejigu T. Determinants of unmet need for family planning among currently married women in Dangila town administration, 
Awi Zone, Amhara regional state; a cross-sectional study. Reprod Health. 2015;12:42

12. Korra A. Attitudes toward family planning and reasons for nonuse among women with unmet need for family planning in Ethiopia. Calverton: ORC Macro; 2002.

13. Gebreslasie K. Prevalence and factors associated with unmet need for family planning among the currently married reproductive age women in Shire-Enda-Slassie, Northern West of Tigray, and Ethiopia 2015: a community based cross-sectional study. Pan Afr Med J. 2016;8688:1-9.

14. Lata K, Barman SK, Ram R, Mukherjee S, Ram AK. Prevalence and determinants of unmet need for family planning in Kishanganj district, Bihar, India. Glob J Med and Pub Health. 2012;1 (4):29-33.
15. Bibi Seema, Soom Hurmat, Ghaffar Saima, Pir MA. Met and unmet need for family planning and associated factors in a remote rural area of Sindh, Pakistan. Pak J Med Sci. 2012;28(3):400-3.

16. Austin A. Unmet contraceptive needs among married Nigerian women: an examination of trends and drivers. Contraception. 2015;91(1):31-8.

17. Khan S, Bradley SEK, Fishel J, Mishra V. Unmet need and the demand for family planning in Uganda: further analysis of the Uganda demographic and health survey 1995-2006. Calverton: Macro International Inc; 2008.

18. Khalil SN, Alzahrani MM, Siddiqui AF. Unmet need and demand for family planning among married women of Abha, Aseer Region in Saudi Arabia. Middle East Fertil Soc J. 2018:23:31-6.
Ready to submit your research? Choose BMC and benefit from:

- fast, convenient online submission

- thorough peer review by experienced researchers in your field

- rapid publication on acceptance

- support for research data, including large and complex data types

- gold Open Access which fosters wider collaboration and increased citations

- maximum visibility for your research: over $100 \mathrm{M}$ website views per year

At BMC, research is always in progress.

Learn more biomedcentral.com/submissions 